\title{
EN MIQUEL ASÍN PALACIOS. MÍSTICA CRISTIANA I MÍSTICA MUSULMANA EN LA SEUA OBRA
}

Per

JOSEP VALDIVIA I. VALOR

Resum de tesi doctoral dirigida pel Dr. Dario Cabanelas Rodríguez ofm. Catedràtic de Llengua Arab de la Universitat de Granada. Va ésser llegida el dia 23 de juny de 1983 davant el tribunal pels professors Cabanelas Rodriguez, Soria Ortega, Bosch Vilá, Fórneas Besteiro, Gibert Fenech. Va obtenir la qualificació d'Excel.lent.

\section{Agraïment}

Encara que a tots s'estén la meva sincera gratitud per la seva comprensió i la seva amistat i dedicació, vull mencionar ací, de faiçó explícita, a D. Emilio García Gómez, D. Jaime Oliver Asín (+), D. ${ }^{a}$ Joaquina Eguaras ( + ), als intèrprets de la mística musulmana Sayà'id Idries Shah i Omar 'Alî Shah i al director i ponent d'aquest treball Dr. D. Darío Cabanelas, ofm. que tanta de paciència va necessitar per a mí.

Finalment, vull expressar el meu agraïment a D. ${ }^{a}$ María Izquierdo Gómez, neboda de l'íntim amic d'En Miquel Asín que per mediació de D. a Joaquina Eguaras, em va facilitar tota la correspondència inèdita que em va ésser de tanta utilitat per a la confección d'aquest treball.

\section{ELECCIÓ DEL TEMA}

Amb motiu del centenari del naixement d'En Miquel Asin Palacios, la premsa ha evocat la seva memòria, a la qual van rendir homenatges per part de diversos organismes, com la REAL ACADEMIA ESPAÑOLA, i la SOCIEDAD DE ESTUDIOS 
Y PUBLICACIONES (1). Tots ells van posar de manifest la valuosa herència que em va llegar la persona i l'obra d'Asín.

Fent-nos ressò d'aquesta herència, i donat que els anys transcorreguts ens permeten de contemplar aquest fecund llegat amb una raonable perspectiva històrica, hem intentat de contribuir al seu millor coneixement en aquest modest treball.

Però considerant l'extraordinari volum de l'obra d'Asín, que abasta les més variades matèries, hem elegit com a tema concret del nostre estudi la teoria d'Asín, tocant a les relacions entre la mística cristiana i la mística musulmana, tema de la major actualitat, com es pot veure per tota una sèrie de treballs, que estan realitzant-se en el camp de la investigación científica -i es projecten en el de la divulgació-, sota aspectes tan variats com són, per exemple al filosòfic, el musical, el literari, el psicològic, etc.

Dins de la magna obra d'Asín, ens ha paregut que l'estudi més detallat d'aquest tema seria del màxim interés i podia constituir la clau de la gran majoria de les seves investigacions, per-què, l'aspecte d'aquestes, com intentaré posar de relleu al llarg d'aquest treball, projecta una llum diàfana en el l'estudi comparat del cristianisme i l'islamisme.

En conseqüència, oferiré primerament alguns dels seus trets biogràfics, tractaré el marc històric del seu pensament i valoraré la seva significació com a impulsor d'una Escola.

A continuació abordaré l'estudi de les relacions entre la mística cristiana i la mística musulmana en l'obra d'Asín. Com a complement d'aquesta part i donada sa íntima unió amb el tema assenyalaré breument les teories actuals sobre l'origen del sufisme. Després examinarem la tesi d'Asín davant la crítica en els diversos aspectes del seu context. Per últim oferiré les conclusions que una visió retrospectiva del treball realitzat m'ha permés de formular.

Com a fruit del centenari seria de desitjar que per iniciativa espanyola i amb el suport dels nostres organismes competents i els d'aquells països que poden estar interessats en això, i d'acord amb les Escoles d'Estudis Àrabs de Madrid-Granada, hereves de la sabiduria de D. Miguel Asín, es dirigira una proposta a la UNESCO demanant la publicació de les obres completes del gran mestre de l'arabismo espanyol. Aquest especial homenatge internacional a la figura d'Asín aleshores podria contribuir indubtablement a un major apropament i comprensió entre Orient i Occident.

\section{DON MIGUEL: VIDA I OBRA}

\section{Trets biogràfics}

El 5 de juliol de 1871 va nàixer En Miquel Asin Palacios a Zaragoza, en una casa

(1) Cf. Dionisio Gamallo Fierros, El centenario de un verdadero sabio español (en ABC, 22 d'agost de 1971), on demanava la formació d'una junta nacionai d'homenatge a $\mathrm{D}$. Miguel Asin i esperava que les tres corporacions a les quals ell va pertanyer colaborarien, abans que acabara l'any en sessions públiques dedicades a l'exemplar investigador i pedagog, o que fóra l'institut d'Espanya, com a representació conjunta de les Acadèmies, qui ho fera, ja que ha propiciava la triple condició acadèmica d'Asín. 
del carrer de Les Dances, fill d'una família de modests comerciants d'origen aragonés i riojà.

En els seus anys d'infància va començar la seva educació a l'escola primària de Saragossa, regida per les germanes de Sant Vicent de Pául, al carrer de San Voto. Allí va ser company de Carles Riba Garcia, que hauria de ser després degà de la facultat de filosofia i lletres i cronista d'aquella universitat.

Va iniciar els seus estudis de Batxillerat als Escolapis i els va acabar a l'escola d'El Salvador, que són els jesuïtes de Saragossa i van saber despertar en ell un viu interés per les matemàtiques. Alli va entaular també amistat amb Alberto Gómez lzquierdo, una gran amistat de xiquets, que havia de prolongar-se durant tota la vida i fins després de la mort del seu amic.

Segur en la trajectòria de la seva vida intel.lectual, va nàixer en ell la seva vocació d'arabista amb En Julian Ribera que va ocupar la càtedra d'àrabe a la Universitat de Saragossa en 1887.

Quatre anys més tard el prestigiós Mestre contava entre els seus alumnes al en eix moment jove seminarista, que molt prompte començava a prendre part en la seva vida.

L'encontre d'Asín amb Ribera va ser decisiu tant en la seva vida com en l'àmplia gamma de les seves activitats.

La seva importància en la cadena històrica dels estudis orientals queda manifesta en els treballs que realitza des de 1899 fins a 1944, data de la seua mort, i més encara amb els treballs que foren publicats a títol pòstum des de 1944 fins a 1951.

A les 7 de la vesprada del dissabte 12 d'agost de 1944, exhalava D. Miguel l'últim sospir, rodejat del seu nebot D. Jaime Oliver Asín i la seva família.

\section{Marc històric del seu pensament}

En aquest capítol considerarem la figura d'Asín, analitzant l'ambient intel.lectual de l'època. En aquest temps, en què D. Marcelino Menéndez y Pelayo intentava una valoració de la cultura del nostre passat, se sent la necessitat d'esperits gegants capaços de sistematitzar i revaloritzar eixa cultura. Aquest tret ressalta perfectament en el quefer de D. Miquel Asín i el configura com un preclar investigador de la generació del 98.

Quant als estudis occidentals sobre l'orige del sufisme, que tanta dificultat i problemàtica presentaven en el context internacional del món en occident, trobem a D. Miguel Asín com el màxim estudiós d'aquest tema en l'Espanya del seu temps. Dei$x a$ assendat $D$. Miguel Asín que el sufisme va entrar a l'Islam per imitació, i el defineix clarament com una doctrina nascuda al si de la teologia. Els seus deixebles i les generacions d'hòmens pius que després van succeir sempre van considerar aquest com un camí cap a la veritat.

\section{Asin impulsor d'una escola}

A través de les seves investigacions dona un gran impuls a les escoles de Madrid i Granada. Va facilitar la preparación necessària als pares agustins de la Biblio- 
teca de l'Escorial i així estos van poder redactar el catàleg del manuscrit àrab de la biblioteca. D'entre els seus alumnes arabistes a l'Escola destacaven: Melchor Martínez Antuña, Nemesio Morata, Leopoldo Torres Balbás, Reginaldo Ruiz Orsatti. També el seu nebot Jaume Oliver Asin que va fer importants estudis de toponimia i filologia. Un lloc molt destacat va ocupar Ángel González Palencia. En l'actualitat continua la justa fama d'Emilio Garcia Gómez, tant per les brillants lliçons com pels seus grans treballs d'investigació.

En opinió de Gómez Izquierdo, Asín pertany al grup d'arabistes espanyols que van treballar amb Francisco Codera i amb Ribera. Els tres intenten amb èxit posar de relleu la influència dels musulmans en tots els aspectes de la vida espanyola. Asín en emprendre l'estudi de la filosofia i teologia musulmana, intenta senyalar les seues connexions amb la cristiana, per llevar els prejudicis amb què havia d'ensopegar. Va procurar, dominar els tecnicismes filosòfics de la llengua àrab i va estudiar amb gran escrupulositat la filosofia i teologia cristianes de l'Edat Mitjana. Va merèixer l'aplaudiment unànime dels arabistes pels seus estudis especialitzats i va despertar la curiositat dels historiadors de la filosofia. Apart de les investigacions d'Asín Palacios realitzades en l'àmbit de l'escola d'estudis àrabs, el savi espanyol va realitzar una magnífica labor docent amb els becaris seleccionats entre els alumnes més brillants de la facultat, que van completar el quadre de l'escola (2).

\section{MÍSTICA CRISTIANA I MÍSTICA MUSULMANA EN L'OBRA D'ASÍN PALACIOS}

\section{Els estudis d'Asín anteriors a l'Islam cristianitzat}

Des de 1899 Asín Palacios mostra sa predilecció per l'espiritualitat dels sufís. Influit pel mestre Ribera, que havia vist en Ramon Llull un sufí cristià, inicià per esta via l'estudi de dita espiritualitat. D. Miguel Asín, en emprendre a fons l'estudi del fenòmen místic de l'èxtasi, utilitza les teories de Williams James sobre els místics cristians, però no era el seu propòsit desenvolupar i criticar la tesi del savi nord-americà, sinó eixamplar el camp d'estudi contrastant el misticisme cristià amb el sufisme musulmà.

Estudia el problema de la conciliació del dogma amb la filosofia. Per molt de temps s'han dedecta els filòsofs i els religiosos a una gran enemistat. En quant a la semblança entre Ibn Ruŝd i Sant Tomàs d'Aquino, aclareix que molts punts doctrinals de Ibn Ruŝd eren anàlegs als defensats per Sant Tomàs.

Segons el pensament d'Asín resulta clar com la síntesi teològica de Sant Tomàs es basa en la filosofia i teologia de lbn Ruŝd depurat, naturalment, dels seus errors en contra la fe cristiana.

(2) "Gaceta", 4 de febrer. En 1939, l'escola d'estudis àrabs s'incorpora al Consell Superior d'Investigacions Cientifiques, agrupant-se amb la d'estudis hebraics sota el nom d'Institut «Arias Montano» fins que, a la mort de D. Miguel Asín (1944) va adoptar la denominació de Institut «Miguel Asín» d'Estudis Árabs separant-se dels hebraics.

Quant a la seva llavor transmissora de coneixement, D. Emilio García Gómez fa referència a la semblança d'Asin amb els mistics šadites. Cfr. Ibn Abbad de Ronda, Sah al-hikam al-ata iyya, 11, 61. Apud Emilio Garcia Gómez, D. Miguel Asín, 1871-1944, Esquema de una biografía, en «Al-Andalus», IX (1944), p. 270. 
Quant als orígens de la filosofia hispano-musulmana troba la clau en l'estudi de la fitura de Ibn Masarra. Demostra en esta obra que durant el segle III de la Héjira la figura de Ibn Masarra ve a representar la clau de la tranmissió de l'orient dins de I'Islam espanyol. Observa que després d'anar-se'n aquest a l'orient, al seu torn a Espanya, reprén a Córdova el seu magisteri com un sample asceta en la seva ermita de la serra cordovesa. Adverteix que dubten d'ell les alfaquies, però que a la par s'admiren del seu mètode de perfecció espiritual, distint al dels orientals, encara que se semblava als dos grans sufís orientals: Dû-l-Nûn l'egipci i Nahrŷurî.

Descobreix Asín que lbn Masarra, sota les apariències musulmanes de mutazilisme i bananisme, defén i propaga a l'Islam espanyol el sistema plotinià del pseudoEmpédocles. La seva doctrina se propaga a través dels dos o tres deixebles més directes que el van sobreviure. D'aquesta manera continuaria la cadena hermètica que embaulava mitjançant Ibn Masarra (3), amb els batanés espanyols i a través de l'escola sufi almeriense.

Per tant, queda clar per Asín que Ibn Masarra (4) és en el segle IX l'introductor i propagador del sistema pseudo-Empédocles a Espanya, imbuit amb les doctrines i pràctiques del sufisme.

Demostra també que dins de l'Islam apareixen una sèrie d'hòmens molt religiosos, a imitació dels cristians d'orient i que al seu torn en l'escolàstica oriental s'observa una gran influència de les idees masarries. Aquestes idees haurien de penetrar tant en el sistema de Ibn Al'Arabi sobre el noms divins com en el desenvolupat per Llull «Els cent noms de Déu». Senyala que les «Dignitates» de Llull estan en íntima relació amb les hadras de lbn al Arabí es referma en la teoria de les «Dignitates» de Llull.

L'evident analogia entre Al-Gazzâli i Pascal, demostrada en el seu estudi, la resum en tres punts transcrits a continuació:

$\left.1 .^{\circ}\right)$ Idèntica actitud fideista i escèptica en el problema de la fe, otorgant a la inspiració o al cor o a l'hàbit, com a font de certesa, un valor superior al de la raó.

$\left.2^{\circ}{ }^{\circ}\right)$ Idèntics recursos apologètics per a persuadir els incrèduls envers la conveniència de creure en la vida futura.

$\left.3 .^{\circ}\right)$ Idèntica disciplina mecànica aconsellada per a lograr la fe.

Donades les estretes analogies entre Dant i el místic murcià Ibn al-'Arabí, sobretot en les hipòtesis de la imitació troba una sèrie de coincidències en l'ús d'uns mateixos recursos artístics de caràcter alegòric entre ambdós acentuants estos més concretament al comparar el «Cancionero» i el «Convito» del poeta florentí amb «l'Intérpret dels amors» $i$ «El tresor $i$ les coses» del místic murcià. En definitiva per a $D$. Miguel Asín, Dant, encara que poeta sincerament cristià en programar-se d'escriure un poema a intenció del qual era cristiana i saber que els sufís de l'Islam havien empleat ja abans que ell la ficció poètica d'un viatge d'ultratomba amb alegoria moral de la vida humana en la seva ascensió finsa Déu, va poder molt bé basar-se en ells per a concebre una altra ficció amb perspectiva evangèlica.

(3) Abenmasarra y su escuela, origenes de la filosofia hispano-musu/mana (Madrid, 1914), pp. 92-110. En avant el citaré per Abenmasarra.

(4) Abenmassarra, pp. 116-117. 
Per a aplegar a l'evolució temàtica Asín Palacios va recórrer a la font del gran filòfof i teòlog Al'Gazzali. Ens aclareix Asín també que la majoria dels pensadors musulmans eren a més de filòfos, teòlegs.

Posa de manifest que l'escola dels aŝ'arîes és l'única de les islàmiques que Sant Tomàs va conèixer pel seu nom més vulgar a l'Islam, que és el dels mutakallimun, traduit, més d'una vegada, pel de «Loquentes in legemaurorum», en la suma contra gents (5).

Estableix Asín Palacios la relació entre l'exercici místic d'Al-Gazzāil i l'exercici mistic cristià. Assegura que Ibn Al'Arabi en el seu Futuhāt recorre a texts del Mahāsin d'lbn al'Arif per a documentar i assentar la tesi dél seu panteisme emanatista, la influència del qual ha estat tan fecunda en l'evolució del panteisme islàmic tant iraní com àrab i al seu torn, l'obra de l'almeriense queda il.luminada en algun passatge obscur per al mateix Futūhāt. D'este modo conclou que la mística andalusa hereva del pensament d'ibn al'Arif i de la seva escola almeriense queda il.luminada alguns passatges obscurs per al mateix futuhât. D'este va mantenir enèrgicament esta mateixa actitud de renúncia a través dels segles.

\section{L'Islam cristianitzat}

En esta obra Asín profunditza en les analogies existents entre el sufisme i el cristianisme. Per a ell estes circumstàncies no son casuals. Ressalta el paregut existent entre els llibres de l'ascètic cristià Bar Hebreus i els d'Al-Gazzāilı. Igualment indica que per a Raimon Martí, Al-Gazzāli va ser una font de coneixement. Senyala que Sant Tomàs va seguir principis de pesaor com Ibn Ruŝd e lbn Bāŷŷa i testimonia que el propi Ramon Llull no s'avergonyeix de confessar els préstecs que pren dels sufís per a algunes de les seves obres.

Asín defén clarament el següent: el monacat anterior a l'Islam, el dels pares de la Tebaida i de Síria i Aràbia, s'ofereix avui com a model de doctrines i de via a imitació de la qual i per influx van sorgir:

- L'espiritualitat cristiana occidental.

- L'espiritualitat, oriental, i més tard, occidental.

Quant a la influència del pensament musulmà sobre el cristianisme, no dubta en acceptar la prioritat de les fonts cristianes i al seu torn, la nova assimilació dels mateixos pels cristians a través de la influència islàmica.

Com a mostra d'aquesta semblança, Asín cita el següent paràgraf d'Ibn al-'Arabí: «No busques de Déu altra cosa que Ell, ni la teua aspiració tendesca a un altre objecte a ell. Encara que se t'oferira tot el que en el món existeix, no et detingues. Pren-ho per cortesia, pero persevera en la teua búsqueda. Déu, en efecte, et provarà d'eixe mode, $i$, si et detens, Déu se t'anirà; en canvi quant tingues a Déu res et faltarà» (6).

En este treball demostra el nostre investigador la coincidència d'actitud davant

(5) «El justo medio», pp. 10 iss

(6) El Islam cristianizado (estudio del esufismo» a través de la obra de Aben-Arabi de Murcia), primera edició, Madrid, 1931; p. 214. Més avant el citaré com el Islam cristianizado. 
dels carismes, adoptada per Ibn al-'Arabī i Sant Joan de la Creu, per als dos aquestes actituds si son, més que favorables, proves, també les adversitats són igualment, més que tribulacions espirituals, signe inequívoc del camí de la perfecció que en segueix l'ànima.

Més encara, per la seva singularitat excepcional, pensa Asín que lbn al-'Arabí, junt amb un selecte grup de mística hispano-musulmana, en especial els de l'escola ŝādili deu considerar-se en este aspecte com a precedent de la història general de la mística (7).

\section{Sāadilies i il.luminats}

La gran aportació d'Asín en quant a la relació existent entre els místics saädilies $i$ els il.luminats, radica en el fet que revela la importància que ofereix, per a la història general de la mistica, l'actitud profundament cristiana de renunciar als carismes de Déu adoptà per els sufies hispano-musulmans de l'escola saāilitie (8).

Un d'ells va ser Ibn 'Abbâd de Ronda, molt proper geogràficament i cronològicament a l'escola carmelitana i que ofereix en opinió de D. Miquel Asín, gran interés per l'analogia de la seva doctrina amb el gran mistic espanyol Sant Joan de la Creu. Conclou que, si es prefer detectar en les analogies abans estudiades per ell, un dèbil efecte de casualitat quant al paral.lelisme d'idees, no deixarà d'esglaiar almenys per als historiadors de la mística, el fet que a Espanya, durant el segle XIV, hi hagués un precursor musulmà de Sant Joan de la Creu, amb idees típiques i simbols que s'han conservat fons avui com enigmes indesxifrables, ja que manguen de qualsevol precedent literari (9).

Per a Asin està clar que el mètode ŝàdilíes presenta un gran paral.lelisme amb la doctrina dels alumbrats en especial el quietisme vist per Sant Joan de la Creu en la seva obra: «Pujada al Mont Carmelo».

Per a ell queda clara l'analogia de l'exercici d'oració mental practicat entre els ŝādilies.

\section{TEORIES ACTUALS A PROPÒSIT DEL SUFISME}

\section{Diverses hipòtesis}

1.- Louis Massignon afirma que els problemes del misticisme islàmic són els mateixos que presenta la teologia dogmàtica musulmana. Els seus origens es desenvolupen dins del context islàmic. Els valors musulmans els investiga de tal mena que tot musulmà horat se sent atret per ell (10).

Esteban Lator afirma que els cinc elements que són indispensables per la sath

(7) El Islam cristianizado, p. 215.

(8) En «Al-Andalus» I (1933), pp. 7-79. Apud «Huellas del Islam», Madrid, 1941. El citaré per un precursor.

(9) Un precursor, p. 266.

(10) Louis Massignon, Essai sur les origines du lexique technique de la mystique musumanae, Paris, 1922, 1954 i 1963; pp. 121-123. 
són: intensitat de l'emoció estàtica; experiència de la unió (amb Déu); estat de borratxera (espiritual); percepció d'una veu i estat d'inconsciència (11).

Andrae Tor diu que la via per als ascetes de l'Islam i l'ensenyança dels eremites cristians, és igual. Manté els següents punts:

- El misticisme ascètic, en la seva forma mística típica, és el buscar del ser humà el ser sobre-humà o Déu.

- El sufisme es mou en la direcció contrària. No és el buscar la perfecció sinó el buscar l'acció de Déu.

- L'amor no consisteix en aprendre a amar a Déu, sino en aprendre que Déu ens ha amat. Félix María Pareja parla de dos conceptes principals entre els musulmans a propòsit de la noció d'ascètica i mistica que han rebut molts noms entre els quals sobreixen:

-Zuhd: en idea d'abstenció.

-Tașawwuf: es refereix a la mística en general.

Al que practica el tașawwuf se li diu sufí. Encontra difícil de resoldre la qüestió de les arrels del sufisme que per a alguns és un fenòmen endogen i per a altres no pot tindre un origen exclusivament autòcton.

Explica que el floriment del sufisme se deu a influxs externs com el cristianisme, corrents helenístics, elements iranies i altres presos de religions índies. Per l'amplària del fenòmen, pot ser mescla de cada una d'estes tesis (12).

R. Caspar comenta que des de fa diverses dècades la mística musulmana és un dels temes més tractats dins dels estudis especialitzats d'orient.

Fritz Meier assevera que el lector europeu no trobarà ací molt de profit, i no avançarà en la bona via, si té tendència a acceptar en bloc la psicologia tal com el sufisme la descriu, encara que guanyara molt si els problemes exposats pel sufisme el duen a reconèixer l'aspecte interior de l'existència humana i a reflexionar sobre els problemes pràctics descoberts per esta via exterior.

G.C. Anawati precisa algunes idees d'interés sobre el sufisme. Per a ell l'experiència mística es qualcom essencialment personal. No pot ser interpretat més que a la llum de la vida mateixa de la mística. El sufisme és un fenòmen «accidental» amb respecte a l'animació primera de l'Islam com a Comunitat (13).

Gardet comenta que el problema exposat a la consciència musulmana pel tașawwuf excedeix tota qüestió d'influència històrica (14). Rep dos tipus d'influències: les iranies i les índies. Entendre per «mística natural» el sentit molt precís definit pel senyor M. Oliver Lacombe i Jacques Maritain. Opina que la mística musulmana pot

(11) Esteban Lator, S.I. Una publicación reciente sobre el sufismo, XVI en “Al-Andaluss (1951), p. 366 i nota 2. Per la seva part A. Nichoison respecta la tesis dels sufís sobre la herència directa transmesca pel profeta $i$ té al Qur'ān com a portador d'elements ascètics i mistics mesclats amb altres de diferent natura. Cfr. Sir Thomas Arnold i Alfred Guillaume. El legat d'Islam, Madrid, 1958, capitol dessús misticisme per R.D. Nicholson, p. 266.

(12) Félix M. Pareja. Islamologia, vol. II, p. 639 (Madrid, 1952-1954)

(13) G.C. Anawati i Gardet, Mystique musulmane (1961), p. 18.

(14) Louis Gardet, Segona part. Les experiències sufís. Capítol I, Sufisme e Islam, 1961, p. 79. 
aportar-nos preciosos punts de referència. Solament una via de mística sobrenatural pot, doncs no prejutja aci els resultats, reblir al sufí autènticament assedegat de Déu. Observa que el que cridem la mística musulmana, se formula en àrab com «ilm altașawwuf, la ciència de tașawwuf» i que es presenta com una disciplina amb les seues tradicions $\mathrm{i}$ les seues escoles. No nega les distintes influències, però per controlar-les i per establi-ne pertinentment les bases pensa que seria precís fer encara llargues i minucioses monografies i moltes altres investigacions (15).

Snouck Hurgronje reconeix les influències cristianes en el Pròxim Orient. En quant al problema de l'origen de la mística musulmana es refueix per a ell al de l'origen dels sufís, que pertanyen a una comunitat naixcuda del judaisme i del cristianisme, a on la mística era ja practicada (15a).

Makki parla de la influència del misticisme egipci en l'Espanya musulmana. Per a ell, alguns opinen que aquesta doctrina mística procedeix del budisme, i altres la consideraven com fruit del maniqueisme persa sota l'escorfa de l'Islam. Pensa que a Egipte ha estat on va florir majorment el misticisme (16). Per Rice el sufisme és com el castanyer que creix enmig d'un prat sense que ningú no l'haya plantat o curat per la qual cosa no es pot traçar els seus orígens. El sufisme té grans noms como Maulana Rumi, Ibn al-'Arabī, Yâmi, Mansur, Al-Hallāŷ, dins del món islàmic i inclús fora d'ell. Pensa quel futur del sufisme siga el fer possible la comunicació religiosa entre Orient i Occident (17).

Paul Nwyia comenta que per a molta gent, místic és sovint sinònim de somniador que viu fora de les realitats d'aquest món i fora de sí. Per això per als que preten anar en nom d'un realisme sa i allunyat de tota aventura incontrolable, l'Islam sunní ofereix sospita i és apartat, ja que est s'adjudica per essència el ser la síntesi del religiós i del polític. Comenta el moviment sufi explicant que els centres intel.lectuals del sufisme es desplacen de l'orient mig, devastat per les invasions, capa l'Oest marroquí $i$ andalús, i afegeix que les grans sintesis teosòfiques que van veure la llum després de la mort d'Al-Gazzālī i que són la marca d'aquest període de la mística musulmana, foren, en efecte creats per mestres que no són ni bagdādīes, ni küfíes, ni bașries (18).

2.- Les comunitats derviches contemporànies. En l'actualitat les teories del que representa el sufisme estan expresses, entre altres, en Occident, en els «Documents de Comunitats Derviches Contemporanees» (19), publicats amb motiu del Simposio celebrat en Londres. En aquesta publicació després d'unes aclaracions sobre la paraula persa «derviche» aceptada en àrab com el seu plural «daravis» i d'algunes dades curioses sobre els monesteris i els seus mestres, se'ns presenta una ideologia més completa.

(15) L'Islam Religion et Communauté (Paris, 1967), pp. 229-233.

(15a) Waardenburg, I., L'Histoire de I'Is/am (1963), p. 76.

(16) Ensayo sobre las aportaciones orientales en la España musulmana (Madrid, 1968), pp. 149-151.

(17) Cyprian Rice, O.P., The Persian sufis (1969), pp. 10; 15.

(18) Paul Nwyia, Ibn 'Atâ Allâh et la naissance de la Confrérie sadilite, Beirut, 1972, p. 10.

(19) Weavers Davidson, R., Documents on Contemporary Dervish communities, Londres, 1966, p. 3. El citaré per Documents. 
La paraula «daraviš» es considera generalment d'origen persa derivat del verb: "der-vejtan», "esperar en la puerta», en el sentit d'esperar davant la porta de la il.luminació. En el mateix un corresponsal del «Times» (20) detalla una visita realitzada al monesteri Abshar i comenta l'organització, teories, ceimònies i pràctiques que tenen.

Brook White en posa al corrent sobre els Naqŝbandîes, probablement una de les comunitats sufís més conegudes en occident. Ací generalment els principis dels Naqŝbandîes han estat adoptats sota el terme usual de Tarîqa (el camí). Els sufís estan organitzats en Halqas (cercles), que funcionen sota un mestre, i les Halqas es combinen en una organització completa, la Tariqa. El fet notable a propòsit dels membres occidentals de la Taríqa és que entre ells no si encontrarà el semi-intel.lectual de llargs cabells, el neuròtic que un a qualsevol moviment nou, el que busca la guia, totes són persones actives, directes $\mathrm{i}$ interessants.

Continua White referint que recentment assistí a una reunió de trenta-un delegats provinents d'Europa, als quals dirigí la paraula el Gran Šayj de la Tariqā, Idries Shah Saheb, que és, seus dubte, un descendent directe del Profeta (Pau i benediccions de Déu damunt ell), a més un noble afgan, net de S.A. de Sardhana. En esta ocasió cada u que va prendre la paraula, va donar la Kalima i va posar èmfasi en el fet que la Tariqua està conduint a la Humanitat cap a la veritat mitjançant els mètodes mateixos de la veritat i no per mig de la propaganda i la sofisticació intel.lectual. No hi ha dubte de que eix treball de la Tariqā creixerà i produirà individus que seguiran amb l'activitat que provesca a la humanitat del vincle, necessari en el mon materialista, cap a la veritat tal com ja la coneixem (21).

Es creu que tots els derviches estan lligats per una força cridada anomenada per ells Baraka (levitat, energia especial). A part del grau de guia no existeix la jerarquia.

El gran Mantó autoritat de la supremacia sufí, pertany a un descendent del profeta Muhamad. La forma de presentar l'enseyança canvia permanentment. En l'actualitat dita ensenyança es du a terme mitjançant la meditació sobre un tema senyalat per un mestre d'acord amb la seva apreciació de les necessitats de l'alumne la contemplació profunda per incrementar els poders i les habilitats, exercicis de grup entre els quals es compten les ben conegudes danses derviches. Les practiques inclouen un exercici conegut o com el Qiff (en àrab «Para») utilitzant la paraula «Hul». Una altra pràctica és la lletania, anomenada el Dikr (literalment, «repetició»). També hi ha sessió de curació (22). En el «Estudi de tècniques especialitzades en l'Asia Central», Ja' 'far Hallajdi tracta dels processos psicoterapèutics, entrenament, diagrames, i objectius. Segon aquest:

«El mandat d'ensenyar aquesta tècnica encara està en mans de la família Haŝemita (de la qual era membre Muhammad) i els capitans actuals que el conservar són els tres mascles majors de la família, els princeps Ikbal 'Alí Shah, Idries Shah i 'Omar

(20) En el monasterio Abshar, en Documents, p. 4.

(21) Brook White, Selim i M. Ghalib Fidai, Sufism in Changing World, «Siraat", Delhi, vol. I, n. ${ }^{\circ} 5$, January 1 , 1961. Apud Brook White, Selim, Dervish Assembly in the West, en Documents, pp. 7-8.

(22) Omar Michael, Solo to Mecca and Tunisian Caravan, dos brillantes artículos aparecidos en «Blackwood's Magazine», vol. 290, n. $^{\circ} 1.754$ (diciembre, 1961), pp. 481-595 i vol. 291, n. ${ }^{\circ} 1.756$ (febrero, 1962), pp. 123-135; apud Travels and Residence with Dervishes en «Documents», p. 9. L'esmentaré com Travels and Residence. 
'Alí Shah. Després es pot considerar que el coneixement i el poder hipnòtic que tenen deriva de tres fonts que són pràcticament sufís, el que els dóna el poder curatiu de Bahauddin; que són capitans de les tribus i que són Saya'id, descendents de Muhammad» (23).

3.- Idees psicológiques d'ldries Shah. Les idees en matèria de psicologia que Idries Shah ha obtingut de la literatura i del pensament sufí publicades en els seus llibres han suscitat un gran interés en els savis de nombrosos països.

Els pensaments de Shah i el seus profunds estudis estan basats en el sufisme científic conegut per Al-Gazzäli, no en el sufisme d'observació i repetició. El gran treball d'Idries Shah, «The Sufis» (Els Sufís), és un important estudi del pensament sufí i els seus efectes, en l'Orient i l'Occident, introduït en termes complementaris per l'autor anglés contemporani Robert Graves. La seva deovoció en l'estudi del pensament sufí i la seva aplicació als problemes diaris de les comunitats l'han honrat amb l'aprovació del món occidental.

En totes les seves obres intenta servir de baula entre els pensadors d'orient occident, com «The way of the Sufi» (El camí dels sufies), «Wisdom of the Idiots» (Sapiència dels Idiotes), «Tales of the Derviches» (Contes dels Derviches).

Quant a les idees d'Idries Shah, referents als sufies i el sufisme en el seu llibre «The Sufis» refereix que, res més lluny de la seva intenció en escriure que el que puga ser considerat com hostil a l'erudició o al mètode acadèmic:

Segons Shah, els sufies no s'aferren a cap convencionalisme. Alguns usen amb fortuna el format religiós, altres la poesia romàntica, alguns el acudits, contes i llegendes i altres es basen en obres d'art i productes d'artesania. El propi Shah utilitza les històries humorístiques de la figura del «Mulla Nasrudín» com una de les manifestacions de l'ensenyança en la tradició sufí.

4.-- Estudis sobre Nasr Al-Din en l'escola d'arabistes espanyols. El més directe deixeble de D. Miguel Asín, García Gómez, en la seva antologia per l'ensenyament de l'àrab, Antologia àrab per a principiants (Madrid, 1952), utilitza algunes de les històries humorístiques de Ŷehä, com són les que apareixen en els estractes del "Kitab Alif Bâ» d'Ibn al Šayj de Málaga, "Dos històries del ximple Ŷ́ehā̄.

Dins de la mateixa Escola, el professor Granja amb gran erudició dóna a conéixer aquestes amb gran erudició les mateixes anècdotes en el seu estudi «Tres contes espanyols d'origen àrab». Altre interessant estudi sobre aquestes històries tradicionals en Espanya és el titular «Contes àrabs den el Sobremesa de Joan de Timoneda». Tracta el professor Granja aquestos contes trobant paralles precedents en altres contes àrabs.

5.- Conclusions de Shah respecte al sufisme i el seu origen. Shah inclou el sufisme com l'hereu del coneixement i sapiència de les sufis. Les teories del sufisme no pertanyen al pensament oriental sinó en la mida que han guardat certes creen-

(23) Travels and Residence, pp. 10-12; inserit igualment l'interessant estudi Among the Dervishes, del mateix autor, The Octagon Press, Ltd., 14 Baker Street, Londres, 1973. 
"cies caigudes en desús en occident. Quant a l'origen del sufisme, pensa que hi ha hagut sufis en tots els temps i en tots el països abans de l'Islam. Els sufís han produiit grans teòlogs, poetes, i homes de ciència. Han acceptat la teoria atòmica i formulat una ciència de l'evolució 600 anys abans de Darwin. Shah considera als sufís com predecessors dels místics $i$ dels filòsofs.

\section{La tesi d'Asín davant la crítica}

1.- Alguns comentaris generals sobre Al-Gazzālı i lon Masarra, Menéndez Pelayo, Wensink, Jeffery, Beaureueil i Anawati, Henry Corbin i Louis Gillet.

Menéndez Pelayo reconeix que Asín s'ajusta perfectament al coneixement de la teodicea i que el gran interés d'Asín estreba en haver indagat i posat en el seu punt els vertaders i complicats orígens de la mística d'Al-Gazzālī.

Wensink pensa que l'obra capital d'Asín Palacios ha difòs tota la llum desitjable sobre el tema de les influències del platonisme i cristianisme sobre Al-Gazzālı (23a).

Jeffery en breus paraules recorda la importància de l'estudi d'Asín sobre lbn Masarra a través del qual hem pogut conèixer l'empremta que va deixar el filòsof cordovés, no sols en el pensament musulmà a través d'lbn al'Arif i ibn al-Arabì sinó també sobre el filòsof jueu Šelomo Ibn Gabirol (Avicebrón) i els cristians pretomistes, aixi com en el pensament de Bacon i Ramón Llull. Aquest assag - diu Jefferyha estat a dels més àmpliament útils de tot el que Asín ha produilt (24).

Per a Beaurecueil i Anawati, la teoria d'Asin Palacios en trobar el punt de contacte entre Al-Gazzāli i Sant Tomàs en l'existència de Déu demostrada per les idees de la necessitat, està subjecta a tela de judici. No obstant, en opinió d'aquests autors, es deu excusar al savi orientalista, pero esta inexactitud d'interpretació, car reconeixem que es troba d'una insignificància comparada amb la ingent llavor duta a terme sobre el pensament, sobretot moral, d'Al-Gazzāli (25).

Henry Corbin refereix que Asín Palacios ha revelat acuradament la importància del neoempedoclisme, al mateix temps que es complaïa en vore en els deixebles d'Ibn Masarra, els continuadors de la gnosis de Prisciliano.

Aferime Louis Gillet en el seu estudi comparat «Pascal et Gazzäli» que de tots els erudits que han ajudat a traure estes vegades a la llum, ningú mereix tant reconeixement com l'il.lustre professor de la Universitat de Madrid, D. Miguel Asin Palacios. Opina d'ell que per als seus estudis té curiositat de savi, i que per la seva caritat de sacerdot la seva ciència s'il.lumina amb amor (26).

2.- L'Escatologia musuimana de la Divina Comedia. La teoria que va presentar Asín respecte est tema va tindre impugnadors la poièmica dels quals en alguns mo-

(23a) Algazel, dogmática, moral i ascètica, amb próleg de Menéndez i Pelayo (Zaragoza, 1901) (pp. VII I XXXIV); pp. IX-XXIII.

(24) Jeffery. A. Miguel Asin, en «The Muslim world», 35 (1945), p. 273.

(25) S.L. Beaurecueil, O.P. i G.C. Anawati, O.P., en «M.I.D.E.O.» (1956), pp. 207-258.

(26) Louis Gillet, Pascal et Ghazzali, en «Revue des deux mondes», LXX (15 de agosto de 1942), p. 420. 
ments va ser pujada de to, D. Miguel Asín amb gran equilibri i humildat, però fidel a les seues idees, va rebatir cada qual en el seu propi terreny (27).

La seva opinió al respecte, és que la seva hipòtesi de la imitació no s'induix d'unes poques analogies soltes, sinó del conjunt de totes, la qual cosa és totalment impossible que es dega a coincidències fortuïtes.

Algunes de les polèmiques més destacades són les de:

Gabrielli, que com Rajna i Mazzoni, nega la imitació. A més opina que en «La Divina Comedia» que per a ell, fàcilment pogueren ser d'origen cristià, troba analogies tan particularitzants i típiques que denuncien estret parentesc d'idèntica família.

Caballera suposa que Dante va aprofitar solament algunes paraules de les lectures clàssiques i per les seves pròpies reflexions va saber traure desenvolupaments nous (28).

Massignon opina que en «La Divina Comedia» no hi ha més que insignificants còpies directes de l'escatologia islàmica (28a).

Sanvisentí pel seu lloc afegeix que s'estranya de que l'obra escatològica artística dels orientals no tinguera continuació en el seu pais d'origen, entre els cultivadors de l'art al.llegroric, i sense cap empatx s'adherix a la teoria d'Asín i afegeix alguns judicis que comproven el caràcter ascètic dels de Dant (29).

2.1.- Comentaris de Muñoz Sendino, Cerulli, Levi della Vida, Massignon, Cruz Hernández, Idries Shah i 'Omar 'Ali Shah.

Muñoz Sendino diu que encara que Dant va nàixer físicament a Florència, el seu ser intel.lectual i poètic és propi de tot l'occident cristià medieval, el qual va subministrar quants elements de desenrotllament i creixença intel.lectual, espiritual i líric que pugué necessitar (30).

Cerulli va establir per a sostindre les seues hipòtesis comparacions entre episodis de «La Divina Comedia» i passatges d'alt nivell artístic e intel.lectual dins de la literatura àrab. Senyala que Dant no coneixia l'àrab i que eixes obres de la literatura àrab no havien estat traduïdes en l'època d'Alighieri a ninguna llengua europea (31).

(27) La Escatologia Musulmana en «La Divina Comedia», Madrid, 1923; reedició Madrid, 1961; p. 520. L'esmentaré com Escatologia.

Encara que no sempre queda clara la postura d'aquestos autors, solen presentar-se favorables a la tesi d'Asin: Alfa, F. Beck, M. Bencheneb; A. Bonucci; O. Browning; A. Cabaton; A.L. Carballeira; J. Cassou; H. Cochin; A. Codazzi; A.S. Cumming; R.L. Doyon; C. (S.J.) Eguia Ruiz; G. Gabrieli; Gaudefroy-Demonbynes; A. González Palencia; A. Guillaume; M. Heier; Ch. B. Jordán; M.E.; D.B. Macdonald; G. Maurevert; F. Nau; Ostern; Ovemons; C. Pitolet; I. Pizzi; B. de los Ríos; M. Roques; M. Ryan; J.J. Salverda de Grave; W. Soderhjelm; J. Subirá; F. Vayi; F. Van Lieghem; J. Vising; W.H.K. Adversos: A.G. Amezúa; un anónimo; R.P. Busnelli; F. Caballero; B. Hauvette; D.M. Lang; A. Licitra; Paget Tounbee; E.G. Parodi; L. Pictrobono; P. Raina; V. Rossi; B. Sanvisenti; F. Toiracca; G. Vitaletti; Vacilantes: G. Mazzoni; P.P.; E. Pavolini; A. Beilesort; A. Nallino; B. Nardi; G. Gabrieli, G. Levi della Vida; L. Massignon.

(28) Cir. Escatología, pp. 512-518.

(28a) Cfr. Escatologia, p. 521

(29) Escatología, pp. 519-548.

(30) Muñoz Sendino, próleg de "La escala de Mahoma", Madrid, 1949, pp. XII, XIV, XVI, XVIII.

(31) Il libro della Scala a la questione delle fonti arabo-espagnole della Divina Comedia. Cittá del Vaticano, 1949 (Studi e testi, $n^{\circ}{ }^{150}$ ). 
Levi della Vida fa una magistral ressenya sobre l'«Escatologia» i mostra que la millor prova de la inmediata $\mathrm{i}$ indiscutible evidència de la relació entre el Mi raŷ $\mathrm{i}$ «La Divina Comedia» la proporciona la substancial concordança del paral.lel establert tant per Sendino com per Cerulli (31a).

Massignon presenta el seu reconeixement damunt la vàlua investigadora d'Asín. Coneix particularment el tema, que va tractar tan amplament del problema de la interdependència intel.lectual entre Orient i Occident en l'edat mitjana així com el problema dels origens orientals de «La Divina Comedia» i discrepa en alguns punts amb els arguments de l'historiador. La seva opinió final és que per a Miguel Asín el que importa es que aquestos temes escatològics, conserven per a les voluntats de les persones i de les col.lectivitats, una significació directriu permanent (32).

Cruz Hernández destaca les dos tesis fonamentals d'Asín que van obrir camins insospitables. En la primera descubreix l'existència d'una peculiar espiritualitat en l'Islam i en la segona demostra la influència de la primitiva espiritualitat en els primers temps de I'Islam (33).

Idries Shah i 'Omar 'Alì Shah concorden en el fet que Ramon Liull prengué d'Ibn al-'Arabi materials literaris, encara que complementàriament insistiera aquest sobre la importància dels exercicis necessaris per a completar les experiències sufís (34).

També comenta la tesi d'Asín Palacios el princep afganí Sayyed 'Omar 'Alí Shah, germà d'ldries Shah, i igualment líder del sufisme, i a qui beneixen junt al seu germà i la seva família els seguidors d'aquest moviment en l'actualitat.

Coincideix amb el nostre savi investigador en el fet que la descripció de Dant sobre l'Infern, el Paradís i la visió beatífica, es molt pròxima a la d'Ibn Al-'Arabi i així mateix es d'acord que no és fàcil que puga tractar-se d'una simple coincidència (35).

3.- Comentaris d'Arnáldez i Arberry sobre Ibn, Hazm, al-Gazzâli e lbn al-'Ara$b \overline{\text { i }}$ Arnáldez estudia amb amplitud els següents treballs d'Asín Palacios: «un còdex inexplorat del cordovés Ibn Hazm», «Abn Hazm de Córdoba i la seva història crítica de les idees religioses «Els caràcters i la conducta», "L'origen del llenguatge i problemes connexs en Algazel, Ibn Sidâ e Ibn Hazim». Va estudiar l'estructura, les condicions del pensament musulmà i crítica la cristianització dels termes islàmics que le seran propis a Asin (35a).

Arberry va comentar sobre Massignon que va establir una bona base per als futurs estudiosos i començà a estabilitzar la importància de l'aprenentatge del voca-

(31a) Nuova luce sulle fonti islamiche della Divina Commedia, en «Al-Andalus», XIV (1949), pp. 376-407.

(32) Massignon, L., Les recherches d'Asin Palacios sur Dante, Opera minora, tomo I, Dar el-Maaref, Beirut, 1963, pp. $57-81$

(33) Miguel Cruz Hernández, la raíz común de la religiosidad del «mundo de la profecía» y la posibilidad de las relaciones entre la escatología islámica y la Divina Comedia, en «Revista de la Universidad de Madrid», XIV (1965), n. ${ }^{\circ} 53$, pp. 51-52. L'esmentaré com La raiz común.

(34) Les soufis et l'esoterisme (Paris, 1972), pp. 129-130.

(35) Shaik Muslihuddin Saadi Shirazi, le jardin de roses (Culistán). Traducción y prefacio de 'Omar 'Ali Shah (Paris, 1966), p. 12.

(35a) R. Arnáldez, Grammaire et théologie ches Ibn Hazm de Cordou (Paris, 1956), p. 320. 
bulari tècnic del sufís com un preludi essencial per a connectar i dilucidar la seva doctrina (36).

4.- La tesi d'Asín en l'Islam cristianitzat i en les sàdilies. Comentaris de González, Jean Herber, Massignon, Cruz Hernández, S. Gómez Nogales, Míkel de Epalza, Márquez, Gardet i Anawati, Nwyia, F.M. Pareja i Shah.

El deixeble d'Asín, Angel González Palencia, comenta «L'Islam Cristianitzat» i afirma que en ell demostra com el monacat cristià, amb les seves pràctiques i el seus sistemes va servir de model a les congregacions ascètiques i místiques dels musulmans, basant-se per a la seva documentació principalment en els llibres d'Ibn al-'Arabī, que també conegué i amb els quals estava tan familiaritzat. Testimonia que $D$. Miguel Asín demostra en aquest estudi que l'Islam està influït per altres doctrines anteriors, tals com les neoplatòniques, cristianes, i inclús budistes i, precisament en el punt més sensible, que és la concepció i ejecució de la vida religiosa, així com l'experiència mística.

Per a González Palencia el valor dels estudis de D. Miguel Asín sobre el gran teòleg musulmà al-Gazzālī, queda de manifest en «'espiritualitat d'Algazel i el seu sentit cristià», a on segueix l'orientació de les «Logia et Agrapha Domini Jesu» i de «L'Islam Cristianitzat» puntualitza amb la seva erudició, l'origen cristià de moltes idees fonamentals de l'ascètica algazeliana, amb el qual obri un nou camí a les investigacions especialitzades com Lammens, Tor Andrae, Ahrens i Nau, vénen fent per conéixer la sèrie d'idees que s'entremesclen en la concepció i desenvolupament de la religió musulmana (37).

Per a Jean Herber, entre els llibres que han estat escrit sobre Ibn al-'Arabi en llengues europees, l'obra de més qualitat és «El Islam cristianizado», de Miguel Asín Palacios. Segueix comentat aquest crític que el mateix Ibn al-'Arabi observa que la perfecció de les virtuts espirituals poden provocar la il.luminació del cor, sense que l'home tinga un coneixement teòric que sobrepasse les veritats elementals de la doctrina, mentre que la comprensió de la teoria metafísica no garantitza la seva realització efectiva. D'altra banda destaca la llavor meritòria d'Asin quant a la traducció espanyola i publicació de la Risälat al Quds o «L'epístola de la Santitat», d'lbn al-'Arabī, baix el títol de «Vida de santons andaluços» a on descriu les vies dels sufís que lbn al-'Arabì va conèixer a Espanya i que foren en la majoria els seus propis mestres espirituals, la qual cosa reconeix que es una valiosa aportació, donada l'obscuritat del sufí espanyol, que fa que el nombre dels seus escrits traduïts en llengües europees siga tan restringit.

Louis Massignon opina que les analogies e identitats de doctrina entre el cristianisme i l'Islam, podeu explicar-se perquè el Qur'ān és també portador de gérmens ascètics i místics que suposen una evolució autòctona. Conta que els sufrís van desarrotllar i van viure dits gérmens per la detinguda meditació en el seu llibre sagrat,

(36) Arberry, A.J., Introduction to the history of sufism. Las conferencias de Abdullh Suhrawardi de 1942, Univer sidad de Calcuta, Oxford, University Press, pp. 46 y 53

(37) Angel González Palencia, Precedentes islámicos de la Leyenda de Garín, en «Al-Andalus», I (1933), pp. 335-355. Necrologia, p. 198 
construïnt així a poc a poc una doctrina i un mètode que ofereix grans semblances amb el de l'ascetisme i la mistica cristiana (38).

Tant Cruz Hernández com Miguel Asín situen l'Islam com la religió mosaica i cristiana dins de l'àmbit geogràfic i històric del «Mundo del profetismo». Amb tota claretat presenta aquest crític el seu pensament referent al paer de Muhammad dintre del mateix. Diu del profeta de l'Islam que va intuir el vell llaç de comunitat del profeticisme oriental, vinculat estretament als pobles semites que eren la gran familia elegiada per Déu per a anar revelant paulatinament la seva veritat als hòmens. La veritat per al profeta, diu, és «la paraula de Déu» que va ser manifestada a través dels profetes i en el temps, aixi Abraham, Moisés i Jesús són escales d'aquesta manifestació, que, per l'Islam, naturalment, va culminar en Mụammad (39).

S. Gómez Nogales coincideix amb D. Miguel Asín en el tema de la influència del sentir dels àrabs sobre la mística cristiana encara que per a ell, on realment no cap dubte de tal influència és en aquell que es rep a Espanya a través de la via dels místics renans alemanys i a més observa un preciós paral.lelisme en la seva mística i la musulmana.

L'opinió de S. Gómez Nogales és que les fonts de la mística musulmana no es redueixen ni tan sols al Qur'ān ni la mística cristiana; les dos són fonts però hi ha a més d'altres com són la Bíblia, la filosofia índia, l'hermetisme egipcià, tota la filosofia persa, el neoplatonisme, etc. (39a).

Míkel de Epalza emet alguns judicis sobre les opinions teològiques d'Asín Palacios i observa la modèstia que demostra en les seues conclusions al respecte. Fa notar els nous camps d'investigació que s'han obert, ja que est crític pensa que un treball general sobre la vida d'Asín, els seus escrits i el seu pensament ompliria un buit important en la historiografia espanyola dels arabistes historiadors de les religions en el segle XX. Aquest permettria de comprendre millor les seves posicions teològiques i les del seu temps, respecte a les religions no cristianes (39b).

Márquez en el seu treball "Origen y Naturaleza del Iluminismo en Castilla» observa l'element semita dels allumenats i afirma que:

«... tractant-se d'una heregia espanyola, en la que el deixament o abandonament juga un paper fonamental, era inevitable que els autors moderns tractaren de buscar el seu origen en fonts orientals tant jueues com islàmiques...» (40).

P. Nwyia ressalta la importància de l'estudi d'Asín sobre les relacions d'Ibn 'Ab-

(37a) Ctr. Muhyî-d-dîn Ibn 'Arabi, la sagesse des prophétes (Fusus al-Hikam), traduccrón y notas por Titus Burckhardt), prólogo de Jean Herbert, París, 1955, pp. 13-14.

(38) Louis Massignon, Les recherches d'Asin Palacios sur Dante. Le probleme des influences musulmanes sur la chrétienté medievale et les loies de l'imitacion litteraire, apud Opera Prima, I, pp. 57-81.

(39) Miguel Cruz Hernàndez, Ibn 'Arabi de Murcia y la espiritualidad cristiano-musulmana, en «Revista de Occidente», año III, 2. ${ }^{a}$ época, n. ${ }^{\circ} 27$ (junio, 1965), p. 317.

(39a) Salvador Gómez Nogales, S.J., Espiritualidad musulmana, en Manresa, 41, 1969, p. 66.

(39b) M. de Epalza, Algunos juicios teológicos de Asin Palacios sobre el /slam, «Pensamiento», vol. 25 (1969), pp. 145-182; 181-182.

(40) Antonio Márquez, Origen y naturaleza del iluminismo en Castilla (1525-1529), «Salmanticensis», 17, 1970 pp. 339-362; 34-347. Text original en castellà. 
bād de Ronda i Sant Joan de la Creu i considera que aquesta semblança deu ser consignada (40a).

Tant per a Gardet com per a Anawait, moltes semblances de l'esperit humà són de fet coincidències situades sota la perspectiva diferent i les fonts comunes que poden ser propostes, a penes influeixen sinó en el ple de préstams materials (41).

F.M. Pareja resumeix el pensament d'Asín Palacios referent a la doctrina šadifi, referit al principi fonamental d'aquesta doctrina exposada per lbn 'Abbad, que la postula de la manera següent: Al-lāh és inaccessible a la criatura. Refereix que Asín Palacios va fer notar que els llibres šadiles es reediten amb freqüència a les premses de El Cairo (42).

Per a Shah l'escola del enllumenats sufies és una de les més famoses i per tant, la més secreta de totes les escoles sufís. Amb el treball d'hòmens com Asín - comenta Shah- el pèndul torna a marxar en l'altra direcció i la influència sufí està en camí de ser reconeguda. Pensa que el contacte amb els sufís va provocar altre desenvolupament interessant en el pensament occidental; procés que encara continua, i el terme que convé millor per a qualificar aquest desenvolupament és el reconeixement (43).

\section{Conclusions}

a) Quant a la persona d'Asín, d'ell mateix es diu, per boca de qui el va conèixer, que tenia talla de místic.

Ens sobra ementar el retrat que li fa el seu deixeble D. Emilio Garcia Gómez, el qual afermax: «era el mestre, tal com el volien els místics šadilies que Asín havia de traduir en la seva obra pòstuma. No serà el teu mestre aquell a qui escoltes, sinó de qui aprens; ni serà aquell que done les seues explicacions sinó aquell que deixe en el teu cor empremta de les seves ensenyances; ni ho serà aquell que el convide a entrar per la porta, sinó aquell que et destape el vel; ni aquell que t'ofereisca les seves paraules sinó aquell que excite en tu els seus mateixos estats espirituals».

Hem observat que també coincideix amb el mistic Al-Gazzālı aplicant-li les pròpies característiques que ell mateix li atribueix: «temperament equilibrat, discret, quasi filòsof, posa en tota la seva mística una justa ponderació, tant distant de les negacions de l'incrèdul i de la sequedad emocional del racionalista, com de la fàcil credulitat del simple fidel i dels entusiasmes fols del místic exaltat; el seu tipus psicològic es sembla dancs, molt al dels cristians ortodoxos com Sant Bernat i Sant Bonaventura».

b) Respecte a la seva teoria, deduïm els punts següents:

1. ${ }^{\circ}$ - Per a Asín, la clau de la semblança entre les dues místiques estaria en

(40a) Paul Nwyia, S.J., Ibn 'Abbâd de Ronda, Beirut, 1961, p. 94

(41) Gardet, L. y Anawati, M.M., Introduccion a la Theologie Musulmane (éssai de theologie comparée), amb prefaci sobre Louis Massignon (París, 1948), p. 289.

(42) Crr. Félix M. Pareja, Historia de la espiritualidad, separata, Barcelona, 1969, pp. 180-181.

(43) Idries Shah, Les Soufis et l'éssoterisme, París, 1972, pp. 215-216. 
les influències mútues, i a ell correspon haver dilucidat la teoria tan extesa en altres èpoques, i especialment en el seu temps, de si havia o no mística a l'Islam, i que hui es reconega que hi existeix una mística.

2. ${ }^{\circ}$ - Aquesta mística musulmana s'origina en les influències del pensament.

En un principi les dels místics orientals cristians i monjos de la Tebaida sobre els musulmans $i$, posteriorment, eixes mateixes influències en el cristianisme d'occident per via de l'Islam, especialment a través d'Espanya, per mig dels místics espanyols musulmans i els seguidors de les escoles sāalilies de místics andalusos i nordafricans.

$3 .^{\circ}$ - La cridà mística musulmana que, per a evitar confusións, deuria cridar-se sufisme contràriament al que pareix, és abans de l'Islam.

$4{ }^{\circ}$ - El sufisme, si bé no va sortir en l'Islam per generació espontània, va trobar en ell condicions suficients per a viure i desembolicar-se una volta imitat.

$5 .^{\circ}$ - Asín posa en el seu punt els veritables i complicats orígens del sufisme i la seva interrelació amb fonts neoplatòniques, índies i hebrees.

6. ${ }^{\circ}-$ Per a Asín, i en això segueix el seu mestre Ribera, hi ha sufís cristians aixi com sufís musulmans, encara que el sufisme s'haja propagat més directament a través de l'islam.

7. ${ }^{\circ}$ - La tesi d'Asín, coincideix amb la tesi actual del sufisme, que segons la filosofia derviche defineix com una manera de viure des de l'antigüitat, més llunyana. De fet no és un sistema místic ni una religió, sinó un cos de coneixements.

$8^{\circ}$ - Les obres dels sufís, com en l'actualitat defineix Idries Shah, intentaren servir d'anella entre els pensadors d'orient i d'occident.

9. - El sufisme no s'estudia a través de llibres sinó a través de la vida mateixa. Per als sufís la figura del Mullâ Nașr ed-dîn representa el ser humà en totes les seves facetes, és a dir, a l'home perfeccionat, complet, al-Insân al-Kamil o sufi.

c) Referent al lloc que correspon a Asín com investigador direm:

$1 .^{\circ}$ - Que amb ell queda clar que en la Història, i especialment entre les segles VIII i XIII, Espanya va ocupar un Iloc fonamental per la intima relació entre la cristiandat i I'Islam, molt particularment mitjançant els mistics.

$2 .^{\circ}$ - Que la importància de tota aquesta relació per mig de la convivència es manifesta en autèntica profunditat en el camp de la mística. Ens pareix obvi la magnitut de la llavor d'Asin en aquest camp.

3. - Asín, com Williams James, estudia l'èxtasi i, després del seu estudi, aferma el valor que tenen aquests fets per a la ciència i la vida, en l'alegria i el plaer moral que produixen. Asín Palacios l'estudia, i tradueix la manifestació d'aquestos fenòmens a l'Islam, fet que indica el valor de la seva obra, car, com ell mateix afirma, ja els savis no poden despreciar eixes vivències religioses, ni identificar-les amb la Història.

Finalment, tots aquells punts ens porten a la conclusió que, així com Espanya 
ocupa un important paper com a anella en la cadena de transmisió del sufisme, portador d'un germen de difusió de coneixements e interrelació entre la cultura oriental i occidental, D. Miguel Asin Palacios ens pareix, entre els grans estudiosos del mistjcisme islàmic, l'anella mes significativa de l'Espanya del seu temps per a l'estudi d'aquest corrent. 